\title{
Efficacy of Natural Enrobing Agents for Adhesion of Seasoning in Roasted Chickpea Snack and Its Acceptability
}

\author{
M. C. Navya, Divya Ramesh, Jamuna Prakash* \\ Department of Food Science and Nutrition, University of Mysore, Mysuru, 570 006, Karnataka, India.
}

How to cite this paper: M. C. Navya, Divya Ramesh, Jamuna Prakash. (2021) Efficacy of Natural Enrobing Agents for Adhesion of Seasoning in Roasted Chickpea Snack and Its Acceptability. International Journal of Food Science and Agriculture, 5(3), 499-509.

DOI: 10.26855/ijfsa.2021.09.021

Received: July 12, 2021

Accepted: August 8, 2021

Published: September 2, 2021

*Corresponding author: Jamuna Prakash, Department of Food Science and Nutrition, University of Mysore, Mysuru, 570 006, Karnataka, India. Email: jampr55@hotmail.com

\begin{abstract}
The objective of the study was to develop a low-fat roasted snack using decorticated chickpea with salt and seasonings. For adhesion of seasonings (three blends) to the roasted grain, natural enrobing material such as cashew nuts, almonds, watermelon seeds, pumpkin seeds, coconut milk and corn flour were used. The efficacy of spice adhesion (measured gravimetrically as leftover spice mix in the packaging container) was evaluated along with storage stability (moisture sorption) and acceptability of the developed product (initial and on storage for 30 days). The adhesive property of almond enrobing agent with chili and pepper spice blend was found to be superior. For chili spice blend with pumpkin enrobe, the leftover spice weight was higher, whereas the watermelon seed based enrobe showed least adhesive property with pepper spice blend. Moisture sorption data indicated that in all samples there was an increase in moisture content as the relative humidity increased, however, even at highest relative humidity, none of the products showed any mold growth on storage. The acceptability trials showed that with chili spice blend, the differences were highly significant for all the sensory attributes except color. For pepper spice blend, the differences were significant for appearance and texture, marginally significant for color and overall flavor and not significant for spice flavor. For all the quality parameters, the chili spice mixture scored highest than the pepper spice mixture. All enrobes were equally accepted by panelists for sensory quality with the exception of corn flour which was given low scores. It can be concluded that oilseed/nut based enrobes were very effective in spice adhesion for the dry roasted chickpea snack and resulted in highly acceptable sensory quality.
\end{abstract}

\section{Keywords}

Low-Fat Snack, Adhesion Properties, Moisture Sorption, Sensory Evaluation

\section{Introduction}

Legume seeds are moderately rich in protein, energy, certain minerals, vitamins and bioactive components. The protein content of legumes is about two to three times greater than that of cereals, hence they serve as primary and important source of protein in plant based diets [1, 2]. Legume based snacks have gained importance due to their nutritional value as they can contribute significantly towards protein intake.

Among the entire legume crops, chickpea (Cicer arietinum. $L$ ) is considered to be the second most important and widely consumed grain. It can be used as whole grain or in decorticated form after cooking or processing. Chickpea flour is also utilized to prepare many dishes, in weaning food mixes, as a supplement, and incorporated into baked goods with other cereal flours. Chickpea has a unique flavour and taste, and has the ability to impart specific textural quality to the product, hence it has been incorporated in many traditional dishes for its functionality [3, 4, 5]. Various 
pre-processing and processing techniques used for chickpea include milling, puffing, roasting, germination, fermentation, steaming, boiling, frying, baking, etc. [6]. Traditionally, whole chickpeas are roasted in sand bath after conditioning to get a puffed grain, with loose outer husk which can be removed. This type of puffed grain has a crisp texture with removal of moisture. It is also one of the dehydration techniques used in development of low-fat product. Minimum nutritional losses take place on roasting, and it reduces or inactivates anti-nutritional factors [7].

In recent decade, consumption trend of snacks is increasing and snacking has become an accepted part of living. In this context, today's consumer is also looking for healthy snack products, which may be protein rich or prepared using natural healthy ingredients. The demand for low-fat snacks is also showing an increasing trend [7, 8]. There are many varieties of snacks available starting from high fat fried products like chips, nutritious granola bars, and baked products to various confections $[9,10]$. There is adequate evidence to show that the consumption of high fat fried foods has a negative impact on human health, and is associated with obesity, dyslipidemia, hypertension, high blood pressure and coronary heart diseases as well as dementia in later life [11, 12]. Many industries have introduced or launched low-fat products by using several technologies such as dehydration, extrusion, roasting, or using fat replacers. Considerable research and development are needed to formulate healthy low-fat products with organoleptic appeal, which is the benchmark for selling any processed food.

To introduce different flavours in snacks, different types of coatings are used, which can add novelty, improve the shelf life, protect ingredients and create texture. For many snacks, oil, sugar or water are used as tack agents, and for wetter ingredients a final drying step is necessary [9]. Hydrated wheat gluten has viscoelastic property and works well as a coating agent, whereas corn protein has also been used for extending shelf life of nut meats, chocolates and coated peanuts $[13,14]$. In case of a dry roasted grain, addition of salt and other seasonings poses a technical challenge as a dry grain does not have any adhesion property. Hence, additives such as hydrocolloids are used as coating agents along with salt and spices to such dry snacks to impart adhesion property [15]. Electrostatic powder coating of foods is also being used in industry for a higher efficiency and even coating [16]. With this background, the objective of present study was to develop a low-fat roasted snack using decorticated chickpea with spice flavourings wherein the efficacy of natural enrobing material such as cashew nuts, almonds, watermelon seeds, pumpkin seeds, coconut milk and corn flour was evaluated along with storage stability and acceptability of the developed product.

\section{Materials and methods}

\subsection{Materials}

The food ingredients needed for the study, namely, decorticated chickpea (Cicer arietinum), powdered spices, chili, pepper, raw mango (used as an acidulant), a commercial spice mix used for garnishing called as 'Chat masala', (it is a ready-to-use blend of common spices such as coriander, pepper, cumin, cardamom, etc with black salt), and common salt were purchased from local supermarket. Oilseeds and nuts, watermelon seeds, pumpkin seeds, almonds, cashew, fresh coconut and corn flour used as enrobing agents were also procured locally. The chemicals used for moisture sorption isotherm were procured from Merck Co. and SD Fine Chemicals, Mumbai, India.

\subsection{Study design}

The study design consisted of developing a roasted chickpea snack using 3 different spices blends and 6 different enrobing agents. A total of 18 products were prepared and evaluated initially for sensory quality and moisture sorption in Phase one. Subsequently, in phase two, these were prepared in larger quantities, stored and analysed for spice adhesion, and sensory attributes through the storage period.

\subsection{Methods}

\subsubsection{Development of roasted chickpea snacks}

(1) Roasting of chickpea

A $100 \mathrm{~g}$ portion of decorticated chickpea was cleaned and soaked in excess water. After soaking for 2 hrs, excess water was drained, and grains spread on a filter paper sheet to remove adhering moisture. The grains were roasted in a heavy bottom pan on a low flame for about 30-35 min to remove all moisture. Different enrobing agents such as watermelon seeds, pumpkin seeds, almonds, cashew, coconut milk and corn flour were made into paste as detailed below, mixed with different spice blends and the roasted grains were enrobed with different enrobing agents while still hot and subsequently dried in a cabinet drier for $30 \mathrm{~min}$ at $50^{\circ} \mathrm{C}$.

(2) Preparation of enrobes

For every $100 \mathrm{~g}$ of chickpea, a $20 \mathrm{~g}$ portion of nuts, namely, cashew nuts, almonds, watermelon seeds, pumpkin seeds, or fresh coconut was used. The nuts were soaked in $20 \mathrm{ml}$ water and ground with spices, whereas for coconut, milk was extracted from ground coconut and mixed with spices. For corn flour, $3.0 \mathrm{~g}$ of corn flour was gelatinized using $20 \mathrm{ml}$ water to make a paste, and then mixed with spice blends. The spice blends used were (1) Chili blend [chili powder $1.0 \mathrm{~g}$, green mango powder $-2.0 \mathrm{~g}$ and salt $-2.0 \mathrm{~g}$ ]; (2) Pepper blend [pepper powder - 1.0g, green mango powder $-2.0 \mathrm{~g}$ 
and salt - 2.0g]; (3) Chat masala [Chat masala - 2.0g and salt - 2.0g]. A total 18 samples, 6 enrobes with three spice blends each, were prepared.

\subsubsection{Moisture sorption}

Moisture sorption of eighteen samples were determined at room temperature $\left(25^{\circ} \mathrm{C}\right)$ using the principle based on Labuza [17]. A $10 \mathrm{~g}$ of sample thoroughly dehydrated in a dry air oven at $50^{\circ} \mathrm{C}$ for $8 \mathrm{~h}$ was placed in weighed petri dish. Duplicate samples were placed in desiccators previously saturated with salt slurries representing different relative humidity. The weight of the products was recorded on alternative days. Different salts used for the study and their water activity were, potassium acetate (22), magnesium chloride (33), magnesium nitrate (54), sodium nitrate (64), ammonium sulphate (84) and potassium sulphate (97). Moisture uptake of samples was computed and expressed as percent moisture [18].

\subsubsection{Storage studies}

The prepared snacks were stored for 30 days in airtight PET (polyethylene terephthalate) bottles at room temperature. The samples were analysed for spice binding efficacy and sensory quality initially and on $10^{\text {th }}, 20^{\text {th }}$ and $30^{\text {th }}$ day.

\subsubsection{Binding Efficacy}

The spice blends adhering to roasted chickpea were checked for the binding efficacy of enrobing agent using gravimetric technique. This process involved weighing of remaining spice mixture in storage container which did not stick on to the grain.

\subsubsection{Sensory Analysis}

The prepared products were coded and subjected to sensory analysis by semi-trained panel members $(n=30)$ with the help of grading score card for appearance, colour, texture, spice flavour and overall flavour. Maximum scores were fixed at 10. The products were evaluated by the panel members in mid-morning and water was allowed in between the samples. On any given day, only one set of products prepared with one spice blend was presented for analysis to reduce any possibility of fatigue [19]. Sensory analysis was carried out in two phases, initially products were evaluated to examine the acceptability of developed snacks in phase I and later in phase II the organoleptic quality of stored products was also evaluated.

\subsubsection{Statistical Analysis}

The sensory data were analysed using suitable tests. Mean and standard deviation was computed for all values and ANOVA was used to test the significant differences between the samples.

\section{Results and Discussion}

The results of the study are compiled in Tables 1-3 and Figures 1-2.

\section{Phase I. Initial acceptability trials and moisture sorption}

\section{i) Initial acceptability trials for the developed products}

Data pertaining to sensory quality of spiced chickpea prepared using different enrobing agents is given in Table 1 . Since the enrobes used in the study have their own aroma profiles, and in addition various spice blends were used, it was interesting to see whether these combinations would result in an acceptable product apart from judging the adhesion efficacy of the enrobes. It may be noted that roasted chickpea is very dry in nature, therefore, unless an adhesive ingredient is used, it is not possible to add on any seasoning to the product. As such chickpea is very bland and addition of spices increases its organoleptic quality. A highly significant difference was observed between samples prepared using chili blend for the attributes of appearance, texture, spice flavor perception and overall quality. However, colour was rated as similar for all samples.

The appearance was rated highest for almonds followed by cashew, coconut, watermelon and pumpkin. The scores ranged between 8.73-9.27. Corn flour was given a low sensory score of 7.37. It may be mentioned here that the sample prepared with corn had a sticky appearance and was not preferred by panel members. The quality of texture, though seemed to be acceptable for all, was least for corn flour enrobed sample with an average score of 8.20, while the range of scores for other samples were between 8.73 to 9.10 . The flavour of chili was most prominent in almonds (8.77) followed by watermelon (8.67), corn flour (8.53) and coconut milk (8.43). Spice flavour was least perceptible in cashew. This could be due to masking of chili flavour by cashew. For overall flavour, pumpkin was liked best, followed by almonds and thereafter coconut and cashew with equal scores. Corn flour had lowest score for overall flavour. The overall results show that enrobe based on corn flour was least acceptable, while others were good.

For many snacks, adhesion of salt is said to increase with increasing surface oil content [20, 21]. In present study, though the roasted grain did not have any surface oil, most of the enrobes used were rich sources of fat and protein, thus forming an emulsion when ground with water. This helped them to develop adhesion properties. Corn flour also exhib- 
ited adhesion property on account of gelatinized starch, however, it had lower sensory scores for flavour.

Table 1. Sensory quality of chickpea snack prepared using different enrobing agents

\begin{tabular}{|c|c|c|c|c|c|c|}
\hline \multicolumn{2}{|c|}{ Details } & Appearance & Colour & Texture & Spice flavour & Overall flavour \\
\hline \multicolumn{7}{|c|}{ Chili spice mixture } \\
\hline \multicolumn{2}{|c|}{ Cashew } & $9.17 \pm 0.87$ & $9.13 \pm 0.73$ & $8.97 \pm 0.67$ & $7.87 \pm 1.14$ & $9.17 \pm 0.53$ \\
\hline \multicolumn{2}{|c|}{ Almonds } & $9.27 \pm 0.74$ & $8.90 \pm 0.71$ & $8.93 \pm 0.78$ & $8.77 \pm 0.50$ & $9.20 \pm 0.48$ \\
\hline \multicolumn{2}{|c|}{ Watermelon seeds } & $8.83 \pm 0.70$ & $9.17 \pm 0.59$ & $9.10 \pm 0.61$ & $8.67 \pm 0.71$ & $9.00 \pm 0.69$ \\
\hline \multicolumn{2}{|c|}{ Pumpkin } & $8.73 \pm 0.87$ & $9.00 \pm 0.64$ & $8.87 \pm 0.73$ & $8.40 \pm 0.81$ & $9.27 \pm 0.69$ \\
\hline \multicolumn{2}{|c|}{ Coconut milk } & $9.13 \pm 0.68$ & $9.00 \pm 0.64$ & $8.73 \pm 0.69$ & $8.43 \pm 0.82$ & $9.17 \pm 0.53$ \\
\hline \multicolumn{2}{|c|}{ Corn flour } & $7.37 \pm 0.67$ & $8.97 \pm 0.93$ & $8.20 \pm 0.85$ & $8.53 \pm 0.63$ & $8.40 \pm 0.68$ \\
\hline \multirow{2}{*}{ ANOVA } & F Ratio & 26.06 & 0.608 & 5.745 & 4.904 & 7.519 \\
\hline & 'P' Value & $0.000^{* * *}$ & $0.694^{\mathrm{ns}}$ & $0.000^{* * *}$ & $0.0003^{* * *}$ & $0.000^{* * *}$ \\
\hline \multicolumn{7}{|c|}{ Pepper spice mixture } \\
\hline \multicolumn{2}{|c|}{ Cashew } & $8.67 \pm 0.66$ & $8.23 \pm 0.77$ & $8.77 \pm 0.94$ & $8.53 \pm 1.22$ & $8.07 \pm 1.01$ \\
\hline \multicolumn{2}{|c|}{ Almonds } & $8.30 \pm 0.88$ & $7.57 \pm 0.94$ & $8.70 \pm 0.88$ & $8.80 \pm 0.76$ & $8.23 \pm 0.94$ \\
\hline \multicolumn{2}{|c|}{ Watermelon seeds } & $8.03 \pm 0.85$ & $7.67 \pm 0.96$ & $8.80 \pm 0.76$ & $8.47 \pm 1.04$ & $7.80 \pm 0.81$ \\
\hline \multicolumn{2}{|c|}{ Pumpkin } & $8.10 \pm 0.84$ & $8.27 \pm 0.87$ & $8.60 \pm 0.86$ & $8.00 \pm 1.17$ & $8.03 \pm 1.22$ \\
\hline \multicolumn{2}{|c|}{ Coconut milk } & $8.10 \pm 0.76$ & $7.83 \pm 0.78$ & $8.70 \pm 0.84$ & $8.60 \pm 0.89$ & $7.83 \pm 1.18$ \\
\hline \multicolumn{2}{|c|}{ Corn flour } & $8.00 \pm 0.95$ & $7.50 \pm 0.90$ & $8.17 \pm 0.75$ & $8.63 \pm 0.85$ & $7.27 \pm 0.98$ \\
\hline \multirow{2}{*}{ ANOVA } & F Ratio & 2.760 & 4.246 & 2.330 & 2.194 & 3.202 \\
\hline & 'P' Value & $0.019^{*}$ & $0.001^{* *}$ & $0.045^{*}$ & $0.057^{\mathrm{ns}}$ & $0.009^{* *}$ \\
\hline \multicolumn{7}{|c|}{ Chat masala spice mixture } \\
\hline \multicolumn{2}{|c|}{ Cashew } & $7.77 \pm 1.14$ & $7.37 \pm 0.67$ & $8.37 \pm 1.00$ & $7.07 \pm 0.78$ & $7.13 \pm 0.78$ \\
\hline \multicolumn{2}{|c|}{ Almonds } & $7.70 \pm 0.92$ & $7.30 \pm 0.79$ & $8.43 \pm 0.77$ & $7.00 \pm 0.91$ & $6.63 \pm 0.61$ \\
\hline \multicolumn{2}{|c|}{ Watermelon seeds } & $7.60 \pm 0.86$ & $7.10 \pm 0.66$ & $8.20 \pm 0.71$ & $6.77 \pm 0.73$ & $7.03 \pm 0.67$ \\
\hline \multicolumn{2}{|c|}{ Pumpkin } & $7.60 \pm 1.07$ & $7.37 \pm 1.07$ & $8.67 \pm 0.84$ & $6.87 \pm 0.57$ & $6.93 \pm 0.78$ \\
\hline \multicolumn{2}{|c|}{ Coconut milk } & $7.40 \pm 1.00$ & $7.23 \pm 0.90$ & $8.03 \pm 0.76$ & $6.77 \pm 0.63$ & $6.87 \pm 0.51$ \\
\hline \multicolumn{2}{|c|}{ Corn flour } & $7.00 \pm 0.79$ & $7.13 \pm 0.94$ & $8.10 \pm 0.76$ & $7.07 \pm 0.98$ & $6.80 \pm 0.76$ \\
\hline \multirow{2}{*}{ ANOVA } & F Ratio & 2.496 & 0.548 & 2.511 & 0.978 & 1.944 \\
\hline & 'P' Value & $0.032^{*}$ & $0.739^{\mathrm{ns}}$ & $0.032^{*}$ & $0.433^{\mathrm{ns}}$ & $0.089^{\mathrm{ns}}$ \\
\hline
\end{tabular}

Values are mean and SD of responses of 30 panellist. Significant differences between enrobing agent on application of ANOVA, marginally significant $^{*}: \mathrm{P} \leq 0.05$, significant ${ }^{* *}: \mathrm{P} \leq 0.01$, highly significant ${ }^{* * *}: \mathrm{P} \leq 0.001, \mathrm{P}>0.05$ : not significant.

The sensory scores and ANOVA of various enrobing agents with pepper blend showed that the appearance profile of products ranged from 8.03 to 8.67 and the differences between samples were significant $(\mathrm{P} \leq 0.0199)$. The scores for colour varied from 7.50 to 8.27 with significant differences among samples. Chili based spice blend was preferred more than the pepper based blend for colour. For the remaining attributes, texture was in a similar range for all (8.60-8.80) with marginally lower score for corn flour enrobe (8.17). For perception of spice flavor, the differences were not significant with all products being given similar scores. Overall flavor was found to be significantly different. Among all enrobes, cashew and almond were favoured more than others, and they blended well with pepper based spice blend. The sensory profile of products with chat masala blend showed a different trend than seen for chili and pepper. Overall the scores were lower for all attributes. The quality of appearance (marginally different among samples) and colour (similar for all) were given lower scores. Texture was rated well, however, spice flavour and overall flavour were given low scores with no differences among products. These data indicate that the spice blends influenced the acceptability of products more than the enrobes employed. However, among all enrobes, corn flour was least acceptable. This can be explained on the basis that corn flour has no aroma of its own, and is very bland when compared with other enrobes which were used. Moreover, corn flour was gelatinized to improve adhesive quality, so, it was sticky in nature which lowered the textural attribute of products.

\section{ii) Moisture sorption of Products}

In food industry, water activity should be controlled and it is very important in preventing microbial growth thereby 
increasing the shelf life of the product. If it is not controlled, it causes the textural changes (crispness and crunchiness) and also changes the rate of chemical reactions (increasing hydrophobic lipophilic reactions but reducing hydrophilic-aqueous-diffusion-limited reaction). The multi-ingredient nature of food and processing commonly results in a range of water activity being present.

The data on moisture uptake of stored snack is provided in Figure 1. In all samples with different enrobing agents, the moisture uptake was least at 22 and 33\%. At 54 and 64\%, there was little increase in moisture uptake. But at the relative humidity (RH) 84 and 97\%, the moisture absorption gradually increased. There were slight differences in moisture uptake pattern on account of enrobing agents and spices. The moisture uptake of samples at RH 22 varied between $0.64-0.90 \%$. On increasing the RH to 33, an increase was seen, which ranged from 1.43-1.97\%. A further increase was noted at RH 54 (3.56-4.49\%) and at RH 64 (6.48-7.46\%). Higher RH of 84 and 97 resulted a higher moisture uptake to about $8.87-10.07 \%$ and $11.25-13.00 \%$. On a closer look, it can be seen that in all samples, there is an increase in moisture content as the RH is increased. However, even at highest RH, it was around $12 \%$, which is permissible for a legume product. None of the products showed any mould growth on storage. A proper packing material will assist in maintaining the storage stability of this snack by preventing moisture uptake.

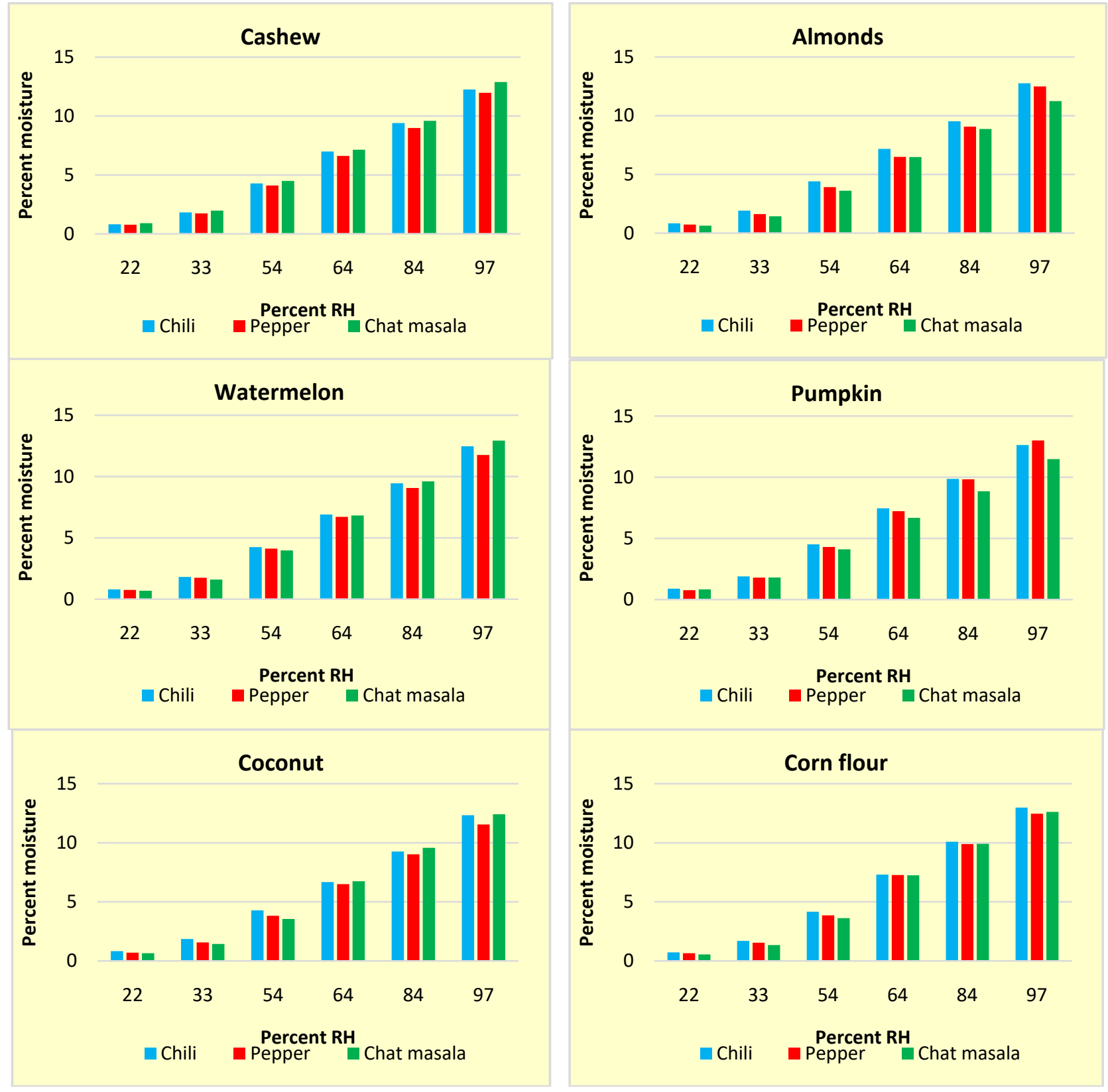

Figure 1. Moisture uptake of products at different relative humidity. 


\section{Phase II. Storage studies}

\section{i) Efficacy of enrobing agents}

The organoleptic quality of dry savory snacks depends on the seasonings used for flavour, which should adhere to the product, examples are potato and tortilla chips which have salt and various seasoning sprinkled on them. A simplest method to evaluate the adhesion or stickiness of added seasonings is weighing the material remaining after the application. A monolayer of food sticks on the adhered surface because of adhesive force and the remaining mass may simply remain there because of cohesive force [15]. In the present study, various natural materials were used as enrobes for adhesion of seasonings to roasted chickpea.

The assessment of efficacy of adhesion of enrobing agents along with spices to the roasted chickpea grain is reported in Table 2. This was measured as leftover spice in the packaging container, in which the snacks were placed. Considering that a total of $4-5 \mathrm{~g}$ of spice powder and salt was used for coating, the leftover spice in the sample was very little indicating that enrobes were able to hold up the spice blends and salt onto the roasted grain. A wide fluctuation in the adhesion of coated ingredient was very evident from the obtained data. In all cases, it was lesser on day 1 and increased gradually over the storage period. Though a specific trend could not be seen, in comparison to chilli and pepper spice blend, chat masala showed comparatively lesser values of leftover spice mixture indicating a better adhesion. Among the various enrobes used, the adhesive property of corn flour with all the three spice mixture was found to be the superior with least removal of spice mixture. Coconut milk also behaved differently as the leftover spice mixture weight was lower for chilli and pepper, whereas for chat masala, the values were found to be higher. This shows that property of enrobes used also influenced the spice adhesion. Corn flour is primarily starch and since it was used after gelatinization, due to sticky nature of starch paste, its adhesion was more. The dry nuts were used in raw form and they exhibited a lower adhesion, though they are naturally a mixture of proteins, fats and CHO. Coconut milk is an emulsion with better adhesion property and no solid material, hence showed better adhesion.

Table 2. Efficacy of different enrobing agents

\begin{tabular}{|c|c|c|c|c|c|}
\hline \multirow[t]{2}{*}{ Enrobing agents } & \multirow[t]{2}{*}{ Spice mixture } & \multicolumn{4}{|c|}{ Leftover Spice Mixture (Weight in g) } \\
\hline & & 0 day & 10 day & 20 day & 30 day \\
\hline \multirow{3}{*}{ CASHEW } & Chilli & 0.145 & 0.246 & 0.204 & 0.675 \\
\hline & Pepper & 0.106 & 0.181 & 0.141 & 0.092 \\
\hline & Chat masala & 0.017 & 0.018 & 0.011 & 0.015 \\
\hline \multirow{3}{*}{ PUMPKIN } & Chilli & 0.443 & 0.355 & 0.339 & 0.218 \\
\hline & Pepper & 0.342 & 0.139 & 0.217 & 0.178 \\
\hline & Chat masala & 0.150 & 0.377 & 0.702 & 0.229 \\
\hline \multirow{3}{*}{ CORN FLOUR } & Chilli & 0.005 & 0.05 & 0.052 & 0.022 \\
\hline & Pepper & 0.049 & 0.04 & 0.045 & 0.012 \\
\hline & Chat masala & 0.027 & 0.025 & 0.013 & 0.003 \\
\hline \multirow{3}{*}{ ALMONDS } & Chilli & 0.128 & 0.144 & 0.302 & 0.187 \\
\hline & Pepper & 0.107 & 0.163 & 0.013 & 0.096 \\
\hline & Chat masala & 0.126 & 0.127 & 0.103 & 0.196 \\
\hline \multirow{3}{*}{ COCONUT MILK } & Chilli & 0.044 & 0.048 & 0.073 & 0.039 \\
\hline & Pepper & 0.035 & 0.057 & 0.038 & 0.019 \\
\hline & Chat masala & 0.144 & 0.197 & 0.276 & 0.112 \\
\hline \multirow{3}{*}{ WATERMELON SEEDS } & Chilli & 0.644 & 0.105 & 0.129 & 0.143 \\
\hline & Pepper & 0.491 & 0.114 & 0.189 & 0.233 \\
\hline & Chat masala & 0.041 & 0.046 & 0.071 & 0.066 \\
\hline
\end{tabular}

The total amount of spice mixture left in the container after 30 days is shown in Figure 2, wherein an inter-sample comparison can be seen clearly. Pumpkin enrobe showed lest adhesion with maximum spice left, whereas the adhesion efficacy of corn flour was maximum. This can be attributed to the pasty nature of gelatinized starch in corn flour which allowed a better adhesion of spice. Among others, though results were varied, it can be seen that adhesion of chat masala was better in two enrobes, and chilli adhesion was least among all. Pepper adhesion was better in almonds, pumpkin and coconut based enrobes. Overall, the selected enrobes were functional in adhesion efficacy with a very small amount of spices being separated at the end of storage duration. 


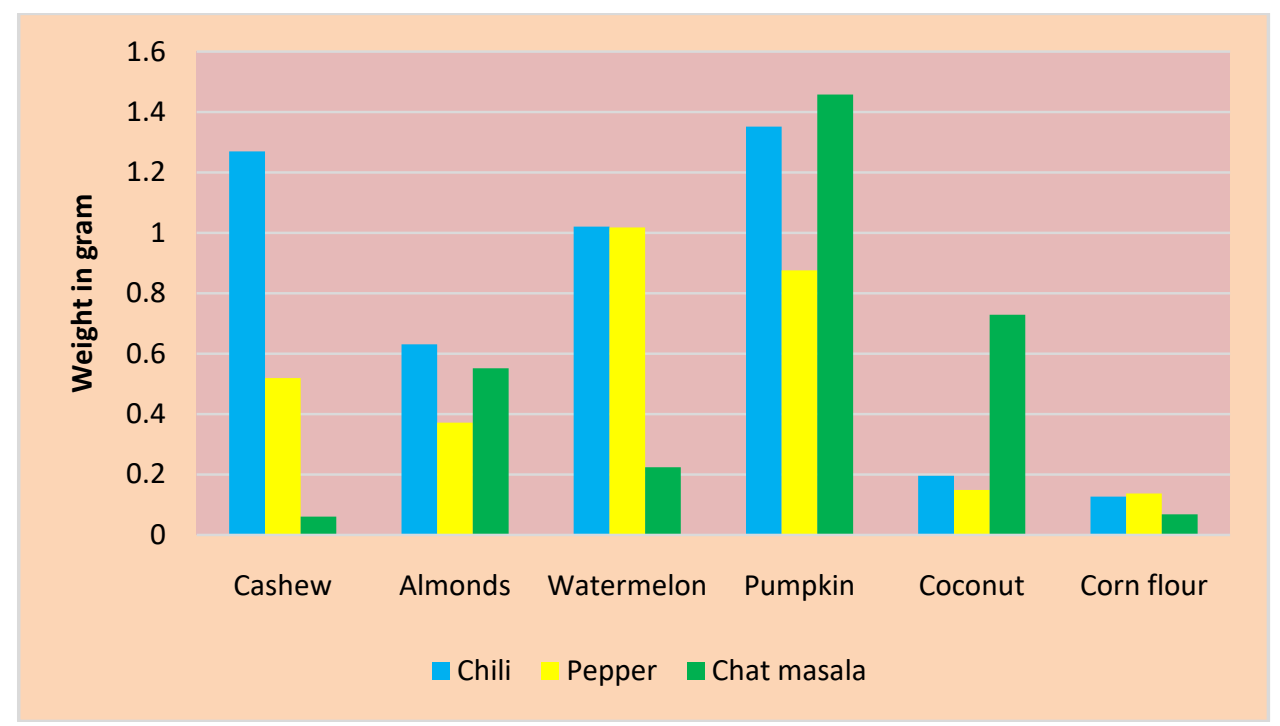

Figure 2. Spice adhesion efficacy of enrobing agents expressed as total amount of leftover spice mixture at the end of storage.

The water imbibition property of macromolecules helps in adhesion. A good wettability indicates that liquid and solid have a strong affinity and are likely to adhere well [22]. It has been demonstrated that adhesion occurs at intimate contact between dry and wet materials and that adequate wetting was a necessary condition for good adhesion [23]. Another factor which influences extent and efficacy of adhesion is viscosity. Reduced viscosity greatly enhances the molecular mobility of the system, which is linked to liquid and solid bridges and also to textural characteristics like stickiness and adhesion [15]. In present study the enrobing ingredients used were all in wet conditions, while the roasted grain was dry. Hence, adhesion of enrobe along with salt and spices was very effective for all spice blends.

\section{ii) Effect of storage on sensory quality of chickpea snack}

The effect of storage on sensory quality of spiced chickpea is compiled in Tables 3A, 3B and 3C.

The data for chilli blend given in Table 3A shows that all the sensory parameters were found to be acceptable up to $30^{\text {th }}$ day when compared between enrobing agents. A gradual decrease in the sensory profile scores was observed for all the product with various enrobing agents, as the days of storage increased. On $0^{\text {th }}$ day, the scores for appearance of the product with the selected enrobes was found to range from 8.80 to 9.30 . On day 10, a very small decrease was observed ( $8.0 \pm 0.00$ to $8.4 \pm 0.52$ ). On day 30 , this score was found to be further reduced, which was in the range of $7.7 \pm 0.48$ to $8.0 \pm 0.47$. The profile of other parameters also indicated a gradual decrease with increase in storage period. The mean score for colour at initial day and on $30^{\text {th }}$ day ranged between 9.00 to 9.5 , and 7.7 to 7.9 respectively. For texture, it was in the range of 8.3 to 8.7 on 0 day and on $30^{\text {th }}$ day, the range varied from 8.1 to 8.6 . The scores for perception of spice flavor were shown to be gradually decreasing with increase in the number of days of storage. This could be mainly due to the fact that most of the flavor compounds in spices are volatile. Even a minimal exposure to external environmental conditions can modify the initial flavor characteristic. Compared to the initial day scores, the scores given for $30^{\text {th }}$ day stored products were comparatively low. The profile of overall flavor also followed a similar trend as discussed above for the other parameters. Among analysed profile the difference between the parameters was not significant. Hence, it can be said that snack products can be stored up to a month with maximum retention of sensory parameters. Beyond this, even if they are stored, it might result in drastic alteration in sensory profile and a decrease in acceptability.

Table 3B provides information regarding sensory attributes of products prepared using various enrobing agent with pepper. The scores recorded for all the sensory parameters were higher and a gradual decrease in sensory score was observed with increase in storage period. The profile of appearance in product stored for 30 days ranged between 7.60 to 8.00 which was comparatively lesser than the scores of initial day products. The profile of color, texture, perception of flavor and overall flavor was also found to follow a similar pattern, i.e., the scores were observed to be gradually decreasing with increase in keeping time. There was no drastic change in the mean scores of products with various enrobing agents stored for 0-30 days. A very small decrease was evident from the data. The differences were not significant for the analysed sensory parameters.

The mean sensory profile and ANOVA of product prepared with chat masala spice mixture by incorporating the selected enrobing agents are presented in Table 3C. The initial day mean scores for all the sensory parameters were comparatively higher than that of products stored for 10, 20 and 30 days. Texture profile was not found to be altered very much and the scores ranged between 8.2 and 9.0 on initial day and in products stored for 30 days, these were in the range of 8.1 to 8.7 . 
Table 3. Effect of storage on sensory quality of spiced chickpea: comparison between different enrobing agents

Table 3A. Chilli spice mixture

\begin{tabular}{|c|c|c|c|c|c|c|c|c|}
\hline \multirow{2}{*}{ Days } & \multicolumn{5}{|c|}{ ENROBING AGENTS } & \multicolumn{3}{|c|}{ ANOVA } \\
\hline & Cashew & Almond & Water-melon seeds & Pumpkin & Coconut milk & Corn flour & F ratio & P value \\
\hline \multicolumn{9}{|c|}{ Appearance } \\
\hline 0 & $9.0 \pm 0.94$ & $9.0 \pm 0.94$ & $9.0 \pm 0.82$ & $9.3 \pm 0.82$ & $9.1 \pm 0.88$ & $8.8 \pm 0.79$ & 0.354 & $0.877^{\mathrm{ns}}$ \\
\hline 10 & $8.4 \pm 0.52$ & $8.3 \pm 0.48$ & $8.3 \pm 0.48$ & $8.4 \pm 0.52$ & $8.3 \pm 0.48$ & $8.0 \pm 0.00$ & 1.054 & $0.396^{\mathrm{ns}}$ \\
\hline 20 & $8.2 \pm 0.42$ & $8.1 \pm 0.57$ & $8.1 \pm 0.57$ & $8.2 \pm 0.42$ & $8.1 \pm 0.57$ & $7.8 \pm 0.42$ & 0.867 & $0.509^{\mathrm{ns}}$ \\
\hline 30 & $8.1 \pm 0.32$ & $8.0 \pm 0.47$ & $8.0 \pm 0.47$ & $8.1 \pm 0.32$ & $8.0 \pm 0.47$ & $7.7 \pm 0.48$ & 1.182 & $0.330^{\mathrm{ns}}$ \\
\hline \multicolumn{9}{|c|}{ Colour } \\
\hline 0 & $9.5 \pm 0.53$ & $9.5 \pm 0.53$ & $9.5 \pm 0.53$ & $9.4 \pm 0.52$ & $9.3 \pm 0.48$ & $9.0 \pm 0.67$ & 1.305 & $0.276^{\mathrm{ns}}$ \\
\hline 10 & $8.3 \pm 0.48$ & $8.2 \pm 0.42$ & $8.2 \pm 0.42$ & $8.3 \pm 0.48$ & $8.2 \pm 0.42$ & $7.9 \pm 0.32$ & 1.182 & $0.330^{\text {ns }}$ \\
\hline 20 & $8.0 \pm 0.47$ & $8.0 \pm 0.47$ & $8.0 \pm \quad 0.47$ & $8.1 \pm 0.32$ & $8.0 \pm 0.47$ & $7.8 \pm 0.42$ & 0.497 & $0.777^{\mathrm{ns}}$ \\
\hline 30 & $7.9 \pm 0.32$ & $7.9 \pm 0.57$ & $7.9 \pm 0.32$ & $8.0 \pm 0.00$ & $7.9 \pm 0.57$ & $7.7 \pm 0.48$ & 0.538 & $0.746^{\mathrm{ns}}$ \\
\hline \multicolumn{9}{|c|}{ Texture } \\
\hline 0 & $8.6 \pm 0.52$ & $8.7 \pm 0.48$ & $8.6 \pm 0.52$ & $8.7 \pm 0.48$ & $8.5 \pm 0.53$ & $8.3 \pm 0.48$ & 0.900 & $0.488^{\mathrm{ns}}$ \\
\hline 10 & $8.7 \pm 0.48$ & $8.8 \pm 0.42$ & $8.7 \pm 0.48$ & $8.8 \pm 0.42$ & $8.6 \pm 0.52$ & $8.4 \pm 0.52$ & 1.003 & $0.425^{\mathrm{ns}}$ \\
\hline 20 & $8.5 \pm 0.53$ & $8.4 \pm 0.52$ & $8.3 \pm 0.48$ & $8.6 \pm 0.52$ & $8.3 \pm 0.48$ & $8.0 \pm 0.47$ & 1.720 & $0.146^{\mathrm{ns}}$ \\
\hline 30 & $8.5 \pm 0.53$ & $8.3 \pm 0.48$ & $8.3 \pm 0.48$ & $8.6 \pm 0.52$ & $8.2 \pm 0.42$ & $8.1 \pm 0.32$ & 1.614 & $0.172^{\mathrm{ns}}$ \\
\hline \multicolumn{9}{|c|}{ Perception of spice flavor } \\
\hline 0 & $8.9 \pm 0.57$ & $8.7 \pm 0.67$ & $8.7 \pm 0.67$ & $8.8 \pm 0.63$ & $8.7 \pm 0.67$ & $9.2 \pm 0.63$ & 0.932 & $0.468^{\mathrm{ns}}$ \\
\hline 10 & $8.3 \pm 0.48$ & $8.3 \pm 0.48$ & $8.5 \pm 0.53$ & $8.3 \pm 0.48$ & $8.5 \pm 0.53$ & $8.7 \pm 0.48$ & 1.075 & $0.385^{\mathrm{ns}}$ \\
\hline 20 & $8.1 \pm 0.32$ & $8.2 \pm 0.42$ & $8.2 \pm 0.42$ & $8.1 \pm 0.32$ & $8.3 \pm 0.48$ & $8.3 \pm 0.48$ & 0.469 & $0.797^{\mathrm{ns}}$ \\
\hline 30 & $8.0 \pm 0.47$ & $8.1 \pm 0.32$ & $8.1 \pm 0.32$ & $8.0 \pm 0.00$ & $8.2 \pm 0.42$ & $8.2 \pm 0.42$ & 0.617 & $0.687^{\mathrm{ns}}$ \\
\hline \multicolumn{9}{|c|}{ Overall flavor } \\
\hline 0 & $9.3 \pm 0.67$ & $9.0 \pm 0.67$ & $9.1 \pm 0.74$ & $9.2 \pm 0.63$ & $9.0 \pm 0.67$ & $8.6 \pm 0.52$ & 1.377 & $0.247^{\mathrm{ns}}$ \\
\hline 10 & $8.2 \pm 0.42$ & $8.2 \pm 0.42$ & $8.2 \pm 0.42$ & $8.2 \pm 0.42$ & $8.2 \pm 0.42$ & $7.8 \pm 0.42$ & 1.500 & $0.205^{\mathrm{ns}}$ \\
\hline 20 & $8.0 \pm 0.00$ & $8.0 \pm 0.47$ & $7.9 \pm 0.32$ & $8.0 \pm 0.00$ & $8.0 \pm 0.47$ & $7.7 \pm 0.48$ & 1.131 & $0.355^{\mathrm{ns}}$ \\
\hline 30 & $7.9 \pm 0.32$ & $7.9 \pm 0.57$ & $7.8 \pm 0.42$ & $7.9 \pm 0.32$ & $7.9 \pm 0.32$ & $7.6 \pm 0.52$ & 0.825 & $0.537^{\mathrm{ns}}$ \\
\hline
\end{tabular}

Table 3B. Pepper spice mixture

\begin{tabular}{|c|c|c|c|c|c|c|c|c|}
\hline \multirow{2}{*}{ Days } & \multicolumn{5}{|c|}{ ENROBING AGENTS } & \multicolumn{3}{|c|}{ ANOVA } \\
\hline & Cashew & Almonds & Water-melon seeds & Pumpkin & Coconut milk & Corn flour & F ratio & $P$ value \\
\hline \multicolumn{9}{|c|}{ Appearance } \\
\hline 0 & $8.6 \pm 0.70$ & $8.5 \pm 0.85$ & $8.4 \pm 0.70$ & $8.4 \pm 0.70$ & $8.4 \pm 0.70$ & $8.2 \pm 0.42$ & 0.371 & $0.866^{\mathrm{ns}}$ \\
\hline 10 & $8.2 \pm 0.42$ & $8.3 \pm 0.48$ & $8.1 \pm 0.32$ & $8.1 \pm 0.57$ & $8.2 \pm 0.42$ & $7.8 \pm 0.42$ & 1.497 & $0.206^{\mathrm{ns}}$ \\
\hline 20 & $8.0 \pm 0.00$ & $8.1 \pm 0.32$ & $7.8 \pm 0.42$ & $7.9 \pm 0.57$ & $7.9 \pm 0.32$ & $7.7 \pm 0.48$ & 1.285 & $0.284^{\mathrm{ns}}$ \\
\hline 30 & $7.9 \pm 0.32$ & $8.0 \pm 0.00$ & $7.7 \pm 0.48$ & $7.8 \pm 0.42$ & $7.8 \pm 0.42$ & $7.6 \pm 0.52$ & 1.256 & $0.296^{\mathrm{ns}}$ \\
\hline \multicolumn{9}{|c|}{ Colour } \\
\hline 0 & $8.8 \pm 0.63$ & $8.8 \pm 0.63$ & $8.5 \pm 0.71$ & $8.7 \pm 0.67$ & $8.5 \pm 0.71$ & $8.6 \pm 0.70$ & 0.415 & $0.836^{\mathrm{ns}}$ \\
\hline 10 & $7.9 \pm 0.32$ & $8.1 \pm 0.32$ & $7.9 \pm 0.32$ & $7.9 \pm 0.32$ & $7.9 \pm 0.32$ & $7.8 \pm 0.42$ & 0.856 & $0.517^{\mathrm{ns}}$ \\
\hline 20 & $7.9 \pm 0.32$ & $8.0 \pm 0.47$ & $7.9 \pm 0.32$ & $7.9 \pm 0.32$ & $7.9 \pm 0.32$ & $7.7 \pm 0.48$ & 0.678 & $0.642^{\mathrm{ns}}$ \\
\hline 30 & $7.8 \pm 0.42$ & $7.9 \pm 0.57$ & $7.8 \pm 0.42$ & $7.8 \pm 0.42$ & $7.8 \pm 0.42$ & $7.6 \pm 0.52$ & 0.446 & $0.814^{\mathrm{ns}}$ \\
\hline \multicolumn{9}{|c|}{ Texture } \\
\hline 0 & $8.7 \pm 0.82$ & $8.5 \pm 0.71$ & $8.7 \pm 0.67$ & $8.6 \pm 0.70$ & $8.8 \pm 0.63$ & $8.3 \pm 0.48$ & 0.697 & $0.628^{\mathrm{ns}}$ \\
\hline 10 & $8.8 \pm 0.79$ & $8.6 \pm 0.70$ & $8.9 \pm 0.57$ & $8.7 \pm 0.67$ & $8.9 \pm 0.57$ & $8.4 \pm 0.52$ & 0.912 & $0.480^{\mathrm{ns}}$ \\
\hline 20 & $8.5 \pm 0.53$ & $8.3 \pm 0.48$ & $8.6 \pm 0.52$ & $8.5 \pm 0.53$ & $8.5 \pm 0.71$ & $8.2 \pm 0.42$ & 0.785 & $0.565^{\mathrm{ns}}$ \\
\hline 30 & $8.5 \pm 0.53$ & $8.3 \pm 0.48$ & $8.6 \pm 0.52$ & $8.5 \pm 0.53$ & $8.5 \pm 0.71$ & $8.2 \pm 0.42$ & 0.785 & $0.565^{\mathrm{ns}}$ \\
\hline \multicolumn{9}{|c|}{ Perception of spice flavor } \\
\hline 0 & $8.5 \pm 0.71$ & $8.7 \pm 0.82$ & $8.8 \pm 0.63$ & $8.6 \pm 0.52$ & $8.6 \pm 0.52$ & $8.7 \pm 0.48$ & 0.282 & $0.921^{\mathrm{ns}}$ \\
\hline 10 & $8.2 \pm 0.42$ & $8.2 \pm 0.42$ & $8.3 \pm 0.48$ & $8.4 \pm 0.52$ & $8.3 \pm 0.48$ & $8.1 \pm 0.32$ & 0.555 & $0.734^{\mathrm{ns}}$ \\
\hline 20 & $7.9 \pm 0.57$ & $8.0 \pm 0.00$ & $7.9 \pm 0.57$ & $8.2 \pm 0.63$ & $8.0 \pm 0.67$ & $7.9 \pm 0.32$ & 0.516 & $0.763^{\mathrm{ns}}$ \\
\hline 30 & $7.8 \pm 0.63$ & $7.9 \pm 0.32$ & $7.8 \pm 0.63$ & $8.1 \pm 0.57$ & $7.9 \pm 0.57$ & $7.8 \pm 0.42$ & 0.476 & $0.792^{\mathrm{ns}}$ \\
\hline \multicolumn{9}{|c|}{ Overall flavor } \\
\hline 0 & $8.8 \pm 0.79$ & $8.7 \pm 0.82$ & $8.8 \pm 0.79$ & $9.0 \pm 0.67$ & $8.7 \pm 0.82$ & $8.3 \pm 0.48$ & 0.982 & $0.437^{\mathrm{ns}}$ \\
\hline 10 & $8.3 \pm 0.48$ & $8.4 \pm 0.52$ & $8.3 \pm 0.48$ & $8.3 \pm 0.48$ & $8.2 \pm 0.42$ & $8.1 \pm 0.32$ & 0.514 & $0.764^{\mathrm{ns}}$ \\
\hline 20 & $8.1 \pm 0.32$ & $8.1 \pm 0.57$ & $8.1 \pm 0.32$ & $8.0 \pm 0.47$ & $7.9 \pm 0.57$ & $7.9 \pm 0.32$ & 0.497 & $0.777^{\mathrm{ns}}$ \\
\hline 30 & $8.0 \pm 0.00$ & $8.0 \pm 0.47$ & $8.0 \pm 0.00$ & $7.9 \pm 0.32$ & $7.8 \pm 0.42$ & $7.8 \pm 0.42$ & 0.856 & $0.517^{\mathrm{ns}}$ \\
\hline
\end{tabular}


Table 3C. Chat masala spice mixture

\begin{tabular}{|c|c|c|c|c|c|c|c|c|}
\hline \multirow{2}{*}{ Days } & \multicolumn{5}{|c|}{ ENROBING AGENTS } & \multicolumn{3}{|c|}{ ANOVA } \\
\hline & Cashew & Almonds & Water-melon seeds & Pumpkin & Coconut milk & Corn flour & F ratio & $P$ value \\
\hline \multicolumn{9}{|c|}{ Appearance } \\
\hline $\mathbf{0}$ & $8.3 \pm 0.48$ & $8.1 \pm 0.32$ & $8.1 \pm 0.32$ & $8.3 \pm 0.48$ & $8.1 \pm 0.32$ & $8.1 \pm 0.32$ & 0.738 & $0.598^{\mathrm{ns}}$ \\
\hline 10 & $8.0 \pm 0.47$ & $7.8 \pm 0.42$ & $8.1 \pm 0.32$ & $8.0 \pm 0.00$ & $8.1 \pm 0.32$ & $7.8 \pm 0.42$ & 1.440 & $0.225^{\mathrm{ns}}$ \\
\hline 20 & $7.8 \pm 0.42$ & $7.6 \pm 0.52$ & $7.8 \pm 0.42$ & $7.8 \pm 0.42$ & $7.8 \pm 0.42$ & $7.6 \pm 0.52$ & 0.514 & $0.764^{\mathrm{ns}}$ \\
\hline 30 & $7.7 \pm 0.48$ & $7.5 \pm 0.53$ & $7.7 \pm 0.48$ & $7.7 \pm 0.48$ & $7.7 \pm 0.48$ & $7.5 \pm 0.53$ & 0.429 & $0.826^{\mathrm{ns}}$ \\
\hline \multicolumn{9}{|c|}{ Colour } \\
\hline $\mathbf{0}$ & $8.3 \pm 0.48$ & $8.4 \pm 0.52$ & $8.2 \pm 0.42$ & $8.3 \pm 0.48$ & $8.3 \pm 0.48$ & $8.2 \pm 0.42$ & 0.257 & $0.934^{\mathrm{ns}}$ \\
\hline 10 & $7.9 \pm 0.32$ & $8.0 \pm 0.00$ & $7.7 \pm 0.48$ & $7.9 \pm 0.32$ & $7.8 \pm 0.42$ & $7.7 \pm 0.48$ & 1.042 & $0.403^{\mathrm{ns}}$ \\
\hline 20 & $7.7 \pm 0.48$ & $7.8 \pm 0.42$ & $7.5 \pm 0.53$ & $7.7 \pm 0.48$ & $7.6 \pm 0.52$ & $7.6 \pm 0.52$ & 0.453 & $0.809^{\mathrm{ns}}$ \\
\hline 30 & $7.6 \pm 0.52$ & $7.7 \pm 0.48$ & $7.4 \pm 0.52$ & $7.6 \pm 0.52$ & $7.5 \pm 0.53$ & $7.5 \pm 0.53$ & 0.415 & $0.836^{\mathrm{ns}}$ \\
\hline \multicolumn{9}{|c|}{ Texture } \\
\hline $\mathbf{0}$ & $8.6 \pm 0.70$ & $9.0 \pm 0.67$ & $8.9 \pm 0.74$ & $8.6 \pm 0.52$ & $8.8 \pm 0.63$ & $8.2 \pm 0.42$ & 2.110 & $0.078^{\mathrm{ns}}$ \\
\hline 10 & $8.7 \pm 0.67$ & $9.0 \pm 0.67$ & $9.0 \pm 0.67$ & $8.7 \pm 0.48$ & $8.9 \pm 0.57$ & $8.3 \pm 0.48$ & 1.987 & $0.095^{\mathrm{ns}}$ \\
\hline 20 & $8.6 \pm 0.70$ & $8.9 \pm 0.74$ & $8.9 \pm 0.74$ & $8.6 \pm 0.52$ & $8.8 \pm 0.63$ & $8.2 \pm 0.42$ & 1.750 & $0.139^{\mathrm{ns}}$ \\
\hline 30 & $8.5 \pm 0.53$ & $8.7 \pm 0.67$ & $8.7 \pm 0.67$ & $8.5 \pm 0.53$ & $8.7 \pm 0.67$ & $8.1 \pm 0.32$ & 1.621 & $0.169^{\mathrm{ns}}$ \\
\hline \multicolumn{9}{|c|}{ Perception of spice flavor } \\
\hline $\mathbf{0}$ & $8.2 \pm 0.42$ & $8.2 \pm 0.42$ & $8.1 \pm 0.32$ & $8.2 \pm 0.42$ & $8.2 \pm 0.42$ & $8.2 \pm 0.42$ & 0.101 & $0.991^{\mathrm{ns}}$ \\
\hline 10 & $8.0 \pm 0.47$ & $7.9 \pm 0.32$ & $7.9 \pm 0.32$ & $8.0 \pm 0.47$ & $7.8 \pm 0.42$ & $8.0 \pm 0.47$ & 0.383 & $0.858^{\mathrm{ns}}$ \\
\hline 20 & $7.9 \pm 0.57$ & $7.8 \pm 0.42$ & $7.8 \pm 0.42$ & $7.9 \pm 0.57$ & $7.7 \pm 0.48$ & $7.8 \pm 0.42$ & 0.241 & $0.942^{\mathrm{ns}}$ \\
\hline 30 & $7.8 \pm 0.63$ & $7.7 \pm 0.48$ & $7.7 \pm 0.48$ & $7.8 \pm 0.63$ & $7.6 \pm 0.52$ & $7.7 \pm 0.48$ & 0.192 & $0.964^{\mathrm{ns}}$ \\
\hline \multicolumn{9}{|c|}{ Overall flavor } \\
\hline $\mathbf{0}$ & $8.1 \pm 0.32$ & $8.2 \pm 0.42$ & $8.2 \pm 0.42$ & $8.1 \pm 0.32$ & $8.3 \pm 0.48$ & $8.1 \pm 0.32$ & 0.450 & $0.811^{\mathrm{ns}}$ \\
\hline 10 & $7.9 \pm 0.32$ & $8.0 \pm 0.00$ & $7.8 \pm 0.42$ & $7.9 \pm 0.32$ & $8.0 \pm 0.47$ & $7.9 \pm 0.32$ & 0.486 & $0.785^{\mathrm{ns}}$ \\
\hline 20 & $7.8 \pm 0.42$ & $7.9 \pm 0.32$ & $7.7 \pm 0.48$ & $7.8 \pm 0.42$ & $7.9 \pm 0.57$ & $7.8 \pm 0.42$ & 0.286 & $0.919^{\mathrm{ns}}$ \\
\hline 30 & $7.7 \pm 0.48$ & $7.8 \pm 0.42$ & $7.6 \pm 0.52$ & $7.7 \pm 0.48$ & $7.7 \pm 0.48$ & $7.7 \pm 0.48$ & 1.020 & $0.415^{\mathrm{ns}}$ \\
\hline
\end{tabular}

It may be noted here that most of the natural enrobes used here have their own flavour profile, which had a synergistic effect of the taste and aroma of formulated product. All nuts/oilseed based enrobes are also known to have excellent emulsifying properties, thus contributing towards better adhesion of seasonings apart from their own nutritional contribution to the snack product. Their emulsifying properties have been used in low fat curries to replace large amount of oil used traditionally resulting in a product with a better organoleptic quality [24]. Water melon seeds are rich in protein, fat and many minerals [25]. Nutritionally almonds are rich in protein with almost all essential amino acids except methionine, and are known for have better fatty acid composition [26]. Almond proteins have been demonstrated to have low viscosity than soy proteins but have higher emulsifying ability. This property can help in better adhesion on the grain [27]. The fatty acid composition of pumpkin seeds is specifically desirable for health [28]. Spices by themselves are associated with multiple health benefits as lipid lowering, hypoglycemic, digestive stimulant, immune boosting and antioxidant effects [29].

\section{Conclusion}

The results of the study can be summarized as follows: initial acceptability trials for roasted chickpea snack revealed that products prepared with oilseeds/nuts enrobes with different seasonings were acceptable for almost all sensory attributes, however, when corn flour was used as an enrobe, scores were lower. The products were stable at different RH with low water uptake except at very high $\mathrm{RH}$, though not crossing the desirable moisture range for storage of legume products. The enrobes were very effective in adhesion of seasonings with very small amount of leftover spice blends in packaging container on storage. The sensory quality of products on storage showed a slight decline, though, they were in acceptable range up to 30 days. It can be concluded that formulated low-fat chickpea snack with different enrobes and spice blends were acceptable for their sensory quality and the enrobes improved their potential nutritional value on account of their own composition and added spices. 


\section{Financial source}

This research work self-funded.

\section{Conflict of interest}

The authors declare no conflict of interest for the work reported in this paper.

\section{References}

[1] Jukanti, A. K., Gaur, P. M., Gowda, C. L. L., and Chibbar, R. N. (2012). Nutritional quality and health benefits of chickpea (Cicer arietinum L.): A review. British Journal of Nutrition, 108: S11-S26. Doi: 10.1017/S0007114512000797.

[2] Hirdyani, H. (2014). Nutritional composition of chickpea (Cicer arietinum L.) and value added products-A review. Indian Journal of Community Health, 26: Suppl S2: 102-106.

[3] Ghavidel, R. A. and Prakash, J. (2010). Composite weaning mixes: formulation and evaluation of quality characteristics. Food Science and Technology Research, 16(1): 65-70.

[4] Romjaun, Z. Z. and Prakash, J. (2013). Development and assessment of fiber enriched muffins. Advances in Food Science, 35(4): 159-165.

[5] Bhavya, S. N. and Prakash, J. (2021) Nutritional properties of iron fortified flatbreads enriched with greens and legumes. Journal of Food Processing and Preservation, 45(5). https://doi.org/10.1111/jfpp.15495.

[6] Oghbaei, M. and Prakash J. (2016). Effect of primary processing of cereals and legumes on its nutritional quality: A comprehensive review. Cogent: Food and Agriculture. 2: 1136015. http://dx.doi.org/10.1080/23311932.2015.1136015. 1-14.

[7] Martinez, A. K. A., Yang, M. M., and Gonzalez de, M. E. (2021). Technological properties of chickpea (Cicer arietinum): Production of snacks and health benefits related to type-2 diabetes. Comprehensive Reviews in Food Science and Food Safety. https://doi.org/10.1111/1541-4337.12762.

[8] Bower, J. A. and Whitten, R. (2000). Sensory characteristics and consumer linking for cereal bar snack foods. Journal of Sensory Studies, 15: 327-345.

[9] Barringer, S. (2006). Coating snack foods. Handbook of Food Science, Technology and Engineering. Vol. 4, Ed. Hui Y. H. CRC Press. USA.

[10] Saldivar, S. O. S. (2016). Snack Foods: Types and composition. Encyclopedia of Food and Health, Elsevier Publications. Pp. 13-18.

[11] Mellendijk, L., Wiesmann, M., and Kiliaan, A. J. (2015). Impact of nutrition on cerebral circulation and cognition in the metabolic syndrome. Nutrients, 7: 9416-9439. doi: 10.3390/nu7115477.

[12] Tripicchio, G. L., Kachurak, A., Davey, A., Bailey, R. L., Dabritz, L. J., and Fisher, J. O. (2019). Associations between snacking and weight status among adolescents $12-19$ years in the United States. Nutrients, 1486, 1-11.

[13] Ponte, J. G. Jr., Dogar, I. S., and Kulp, K. (2000). Special food ingredients from cereals. Handbook of Cereal Science and Technology. II Edn.Edr. Kulp K. CRC Press. USA.

[14] Embuscado, M. E. and Huber, K. C. (2009). Editorial. Edible films and coatings. Springer, USA.

[15] Adhikari, B., Howes, T., Bhandari, B. R., and Truong, V. (2001). Stickiness in foods: A review of mechanisms and test methods. International Journal of Food Properties, 4(1): 1-33.

[16] Khan, M. K. I., Schutyser, M. A. I., Schroën, K. Remko, M. and Boom, R. M. (2012). Electrostating powder coating of foods: State of the art and opportunities. Journal of Food Engineering, 111: 1-5.

[17] Labuza, T. P., Acolt, K., Tatini, S. R., Lee, R. Y., and Flink, J. M. (1976). Water activity determination-A collaborative study of different methods. Journal of Food Science, 41, 911-5.

[18] AOAC. (2005). Official Methods of Analysis, $18^{\text {th }}$ Ed. Association of Official Analytical Chemists: Arlington, VA.

[19] Cadello, A. V. (1998). Perception of food quality. In: Food storage stability. Taub IA, Singh RP, Eds. CRC press: Boca Raton, FL. 1-38.

[20] Enggalhardjo, M. and Narsimhan, G. (2005). Adhesion of dry seasoning particles onto tortilla chip. Journal of Food Science, 70(3): 215-222.

[21] Buck, V. E. and Barringer, S. A. (2007). Factors dominating adhesion of NaCl onto potato chips. Journal of Food Science, 72(8): 435-441.

[22] Michalski, M.-C., Desobry, S., and Hardy, J. (1997). Food materials adhesion: A review. CRC Critical Reviews in Food Science and Nutrition, 37(7): 591-619.

[23] Shanahan, M. E. R. (1991). Adhesion and wetting: similarities and differences. Rubber World, 205(1): 28-36.

[24] Mahesh, P., Gowri, B. S., and Prakash, J. (2007). Utilizing natural emulsifiers for formulation of low fat traditional Indian 
gravy mixes. Journal of Foodservice, 18: 80-85.

[25] Tabiri, B., Agbenorhevi, J. K., Wireko-Manu, F. D., and Ompouma, E. I. (2016). Watermelon seeds as food: Nutrient composition, phytochemicals and antioxidant activity. International Journal of Nutrition and Food Sciences, 5(2): 139-144. doi: 10.11648/j.ijnfs.20160502.18.

[26] Longwah, T., Ananthan, R., Bhaskarachary, K., and Venkaiah, K. (2017). Indian Food Composition Tables. National Institute of Nutrition, ICMR, Ministry of Health and Family Welfare, Govt. on India, Hyderabad., 94.

[27] Sze-Tao, K. W. C. and Sathe, S. K. (2000). Functional properties and in vitro digestibility of almond (Prunus dulcis L.) protein isolate. Food Chemistry, 69: 153-160.

[28] El-Adawy, T. A. and Taha. K. M. (2001). Characteristics and composition of watermelon, pumpkin, and paprika seed oils and flours. Journal of Agriculture and Food Chemistry, 49: 1253-1259.

[29] Srinivasan, K. (2008). Spices as functional food adjuncts with multiple health effects. Indian Food Industry, 42 : 36-46. 